\title{
TALON: shaping the future of online education through connectivity
}

\section{Sandra Abegglen}

University of Calgary, Canada

Fabian Neuhaus

University of Calgary, Canada

Keywords: online education; learning and teaching; networks; collaboration; partnership; Covid-19.

\section{The challenge}

The move online due to the Covid-19 pandemic posed many challenges to academics. These difficulties ranged from access to technology and the internet to developing effective and engaging methods and methodologies for remote delivery, and the struggle to overcome structural bias built into software and applications. The virtual classroom, often praised as the 'future', proved to be far from unproblematic. There were many instances where it appeared to fail those that should benefit from it the most: the students. This raised fundamental questions about the practice of online education: how and what do we teach online? What is the benefit of using technology in education? Who profits from online learning and how? What happens with those spontaneous conversations and interactions - and our emotions - when we meet virtually? And how can we best support students online? However, the biggest challenge appeared to be to find the time and space for reflection and exchange.

\section{The response}

In response to the need for conversations about the move online, we developed TALON, the Teaching and Learning Online Network. The initial aim was to support instructors with the 
transition of their courses to remote delivery. However, TALON's focus soon expanded from providing practical advice on tools and resources to a broader exploration of online education, incorporating and amplifying the voices of academics and students - TALON Voices, available in various media formats including a podcast. This was complemented with an electronic newsletter, the TALON Letter, regularly summarising key developments in the digital classroom from around the world and capturing emerging discussion topics around online instruction and pedagogy. TALON also began developing and creating its own resources, the TALON MAPS (Methods of Appropriate Practice), and it started building a network of interested educators through social media. The TALON website acts as the hub for all these activities and connections with the aim of fostering a sustainable ecology of online education through an active exchange between all those involved in higher education.

What has emerged through this work is a clear manifesto. TALON is committed to and actively advocates for: inclusive and equitable online education; open and positive learning environments; interactive and engaging pedagogy; transformative and imaginative design curricula; empowering virtual classrooms; collaborative learning and design teaching; software and tools enabling meaningful learning experiences; respect and care for all students and instructors (see TALON Manifesto). To achieve these goals, TALON promotes the discussion and the exchange of ideas, cultivating a virtual 'Community of Practice' (Lave and Wenger, 1991; Kimble, Hildreth and Wright, 2001) around new, emerging practices in online higher education. This involves working collaboratively with others, including students, to develop new models and methods. The learning development community is well situated to take a leadership role in this, having education advancement as its focus and being experienced in asking challenging questions to enhance academic practices.

\section{Recommendations}

Since the launch of TALON, we collected 184 resources, conducted 27 voices with 30 people, published 18 letters and recorded 6,849 page views, demonstrating the widespread interest in an exchange about online education. Thus, we encourage others working and teaching in higher education to voice their experiences - the successes and the failures - in the digital classroom and to join the debate about the future of education. 
We recommend that educators, especially learning developers, activate and set up their own networks as nodes in a web of educators. TALON has done this in partnership with other academics, both within and outside its own institutional context, and with students. From the outset, TALON included between two and three Graduate Assistant Researchers (masters' students at any stage of their programme) in the project. This staff-student partnership (Healey, Flint and Harrington, 2014) helped to further enhance the work and the outcomes of TALON as it brought the student perspective directly into the discussion. It proved important as learning and teaching are closely intertwined and cannot be separated (Miller et al., 2019). If conversations are one sided or if they are dominated by a particular group or groups of people, then something important is lost. We all need to shape the digital classroom together.

We therefore recommend that educators actively embrace the 'global reset of education' (Robinson, 2020) brought by the pandemic, and creatively and democratically imagine what education can be, now, and post-Covid-19. This means, as a first step, to make one's own online education work transparent so it becomes open to debate and input. This will then, in a second step, allow the education community to come together and, in a third step, allow it to collectively reflect on what online education might be in the future, and move forward together in a good way. As Shor and Freire (1987) state:

dialogue must be understood as something taking part in the very historical nature of human beings. It is part of our historical progress in becoming human beings. That is, dialogue is a kind of necessary posture to the extent that humans have come more and more critically communicative beings. Dialogue is a moment where humans meet to reflect on their reality as they make and remake it. (p.98).

Together, we can shape the digital classroom and make it an inclusive, empowering learning space that enables all students to participate and succeed. An ongoing and open exchange is key.

\section{Acknowledgments}


The TALON project is funded by the Richard Parker Initiative.

\section{References}

Healey, M., Flint, A. and Harrington, K. (2014) Engagement through partnership: students as partners in learning and teaching in higher education. York: HEA.

Kimble, C., Hildreth, P. and Wright, P. (2001) 'Communities of Practice: going virtual', in Y. Malhorta, Y. (ed.) Knowledge management and business model innovation. Hershey: Idea Group, pp.220-234.

Lave, J. and Wenger, E. (1991) Situated learning: legitimate peripheral participation. Cambridge: Cambridge University Press.

Miller, J. P., Nigh, K., Binder, M. J., Novak, B., Crowell, S. (2018) International handbook of holistic education. Oxon: Routledge.

Robinson, K. (2020) 'A global reset of education', Prospects, 49, pp.7-9. https://doi.org/10.1007/s11125-020-09493-y.

Shor, I. and Freire, P. (1987) A pedagogy for liberation: dialogues on transforming education. Westport, CT: Bergin and Garvey.

\section{Author details}

Sandra Abegglen is a Researcher in the School of Architecture, Planning and Landscape at the University of Calgary and the TALON project coordinator. Her research interests are in digital education, academic literacies, peer mentoring, creative learning and teaching methods, inclusion, visual narratives, identity, and qualitative methods. She is a certified practitioner in learning development, a Higher Education Academy (UK) Fellow, and scientific 
board member for the International Conference on Education in Mathematics, Science and Technology (ICEMST).

Fabian Neuhaus is an Associate Professor at the University of Calgary with the School of Architecture, Planning and Landscape in Canada. He is the principal author of www.urbantick.org and the project lead for TALON (https://taloncloud.ca). His research interests are the temporal aspects of the urban environment, focusing on the topics of habitus, type, and ornament in terms of activity, technology, and memory. He has worked with architecture and urban design practices in the UK and Switzerland as well as on research projects at universities in Switzerland, Germany, and the UK. 